Article

\title{
Flexural Behavior of RC Beams Using Fe-Based Shape Memory Alloy Rebars as Tensile Reinforcement
}

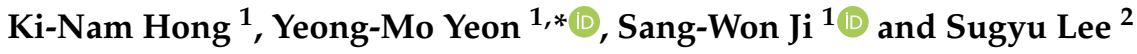 \\ 1 Department of Civil Engineering, Chungbuk National University, 1 Chungdae-ro, Seowon-Gu, \\ Cheongju 28644, Korea; hong@chungbuk.ac.kr (K.-N.H.); tkddnjs0727@chungbuk.ac.kr (S.-W.J.) \\ 2 A Land and Housing Institute, Daejeon 34047, Korea; glee@lh.or.kr \\ * Correspondence: yym235@chungbuk.ac.kr; Tel.: +82-43-261-2377
}

Citation: Hong, K.-N.; Yeon, Y.-M.; Ji, S.-W.; Lee, S. Flexural Behavior of RC Beams Using Fe-Based Shape Memory Alloy Rebars as Tensile Reinforcement. Buildings 2022, 12, 190. https://doi.org/10.3390/ buildings12020190

Academic Editors: Binsheng (Ben) Zhang and Wei (David) Dong

Received: 13 January 2022

Accepted: 6 February 2022

Published: 8 February 2022

Publisher's Note: MDPI stays neutral with regard to jurisdictional claims in published maps and institutional affiliations.

Copyright: (C) 2022 by the authors. Licensee MDPI, Basel, Switzerland. This article is an open access article distributed under the terms and conditions of the Creative Commons Attribution (CC BY) license (https:// creativecommons.org/licenses/by/ $4.0 /)$.

\begin{abstract}
Recently, various studies for the use of Fe-based shape memory alloy (Fe-SMA) in the construction field have been widely conducted. However, most of the studies for using Fe-SMA are carried out for applying Fe-SMA for strengthening deteriorated structures. However, if Fe-SMA is used as a reinforcement for new structures, the disadvantages of conventional prestressed concrete can be effectively solved. Therefore, in this work, an experimental study was conducted to evaluate the flexural behavior of concrete beams in which Fe-SMA rebars were used as tensile reinforcement. For the study, ten specimens were constructed with the consideration of the cross-sectional area and activation of Fe-SMA rebars as experimental variable. Activation of the Fe-SMA rebars by electrical resistance heating applied an eccentric compressive force to the specimen to induce camber. The camber increased by an average of $0.093 \mathrm{~mm}$ as the cross-sectional area of the Fe-SMA rebar increased by $100 \mathrm{~mm}^{2}$. It was also confirmed through the four-point bending tests that the initial crack loads of the activated specimens were $47.6 \sim 112.8 \%$ greater than those of the nonactivated specimens. However, the ultimate strength of the activated specimens showed a slight difference of $3 \%$ to those of the nonactivated specimens. Therefore, it was confirmed that the effect of Fe-SMA activation on the ultimate strength of specimens was negligible.
\end{abstract}

Keywords: Fe-based shape memory alloy; electrical resistance heating; camber; activation

\section{Introduction}

Reinforced concrete (RC) is one of the most important construction materials in practical infrastructure and residential buildings in modern society. However, because the tensile strength of concrete is about eight times smaller than its compressive strength, the cross-section area of concrete should be larger as the length of a concrete member increases [1]. Steel reinforcement is the passive reinforcing material because the reinforcement embedded in the concrete begins to limit the crack width and resist the tensile force after the concrete loses tensile strength [2]. The embedded steel reinforcement inside concrete starts to corrode by either carbonation or by chlorides. Carbon dioxide and moisture in air move through cracks from the concrete surface. The carbon dioxide in air reacts with calcium within the concrete, decreases the $\mathrm{pH}$ value of the concrete, and corrodes the steel reinforcement. In addition, chloride transported through the concrete to steel significantly increases the corrosion rate of steel reinforcement. The corroded reinforcing steel loses load resistance and induces concrete scaling [3].

To control crack development in concrete in service, prestressed concrete has been widely used in civil engineering fields [4]. In contrast to $\mathrm{RC}$, the entire cross-section of prestressed concrete is recognized to be effective in resisting external forces, and this allows reduction of its cross-section area and self-weight. As the compression force produced by the prestressing tendons located in a tension zone of concrete cancels the tensile stress, the crack development can be controlled, and the downward displacement can also be 
controlled by a proper camber in the concrete beam design [5]. However, a hydraulic jack and an anchorage device are required to apply tensioning to the tendons and to anchor the tensioned tendons at both ends of the concrete members, respectively. Their installation and the tensioning process make the construction process complicated and prolong the construction period [6]. Additionally, post-tensioning tendons permanently bonded to the surrounding concrete by in situ grouting cannot be retensioned even if some prestressing force is lost due to drying shrinkage, concrete creep, and tendon relaxation.

To compensate for these limitations, researchers have conducted studies to generate the prestressing force by using shape-memory alloys (SMAs) [7-10]. Unlike steel materials, a SMA material has a shape-memory effect (SME) wherein a material recovers a plastic deformed shape to its predeformation shape when heated above a designated transformation temperature [11]. When the prestrained SMA is activated while restraining the recovery of its plastic deformation, a stress called recovery stress occurs. By using this special characteristic, if a prestrained SMA rebar embedded in concrete is activated, recovery stress occurs because the deformation of the SMA rebar is restrained by the bond force with the surrounding concrete. This recovery stress can be applied as compressive force in the prestressed concrete [12]. The usage of SMA instead of prestressing tendons does not require a hydraulic jack or anchoring device because the SMA is embedded inside concrete and bonding stress occurs during activation. In addition, prestressed concrete exploiting SMA can recover the initial recovery stress by simple reactivation even if the recovery stress is reduced due to dry shrinkage of concrete, creep, and SMA relaxation. However, the commonly known SMA is a Ni-Ti alloy called nitinol, which is not applicable in the construction field because of its higher raw material price [13,14].

On the other hand, since Enami et al. [15] first discovered an iron-based shape memory alloy (Fe-SMA) in 1975, many researchers have studied Fe-SMAs of various compositions. Owing to its cheaper raw material price than nitinol, many researchers and engineers can use Fe-SMA as a construction material. Shahverdi et al. [16] conducted an experimental study on the use of Fe-SMA strips as reinforcement in conjunction with a near-surface mounted (NSM) method. The flexural performance of RC beams strengthened with the FeSMA strips by the NSM method was evaluated by a four-point loading test. They concluded that the initial flexural rigidity was improved in the test specimen with the activated FeSMA using NSM, compared to a specimen with a nonactivated Fe-SMA using NSM. They reasoned that the recovery stress generated by the activation of Fe-SMA acts as prestressing force in the tension zone. Michels et al. [17] conducted an experimental study to evaluate the mechanical properties of Fe-SMA rebars. The diameter of Fe-SMA rebars used in their study was $16 \mathrm{~mm}$, in accordance with the BS standards. They reported that the ultimate deformation of Fe-SMA rebars was about $28 \%$ higher than that of B500 reinforcement. In addition, they reported that the recovery stress of the SMA when prestrained to $4 \%$ and heated to $200{ }^{\circ} \mathrm{C}$ was about $300 \mathrm{MPa}$, and after $1000 \mathrm{~h}$ was reduced by $10 \%$ by SMA relaxation. Hosseini et al. [18] conducted an experimental study to evaluate the recovery stress of Fe-SMA strips under various conditions. They reported that the recovery stress decreased when the activated Fe-SMA strips were subjected to cyclic loads. They also described that the reduced recovery stress could be restored by reactivation of the strips.

However, most of the research for the application of Fe-SMA to the construction field has focused on application for strengthening deteriorated RC structures or evaluating the mechanical properties of Fe-SMAs [19-23]. Very little research has been devoted to evaluating the applicability of Fe-SMA materials as reinforcement for new structures. Therefore, this study was conducted to evaluate the applicability of Fe-SMA rebars as reinforcement for new structures. For the study, beam-type concrete specimens reinforced with Fe-SMA rebars were constructed, and four-point bending tests were performed to experimentally evaluate the flexural behavior of the specimens. In addition, the reactivation experiment of Fe-SMA was performed to examine the possibility of retension of the specimens reinforced with Fe-SMA rebars. 


\section{Experiment Program}

\subsection{Test Specimens}

Ten beam specimens reinforced with Fe-SMA rebars were cast to evaluate their flexural behaviors. As shown in Figure 1, the width, height, and effective depth of the specimens were $250 \mathrm{~mm}, 400 \mathrm{~mm}$, and $350 \mathrm{~mm}$, respectively. Their total and effective lengths were $2800 \mathrm{~mm}$ and $2600 \mathrm{~mm}$, respectively. In order to avoid shear fracture, $\varnothing 13 \mathrm{~mm}$ U-shaped stirrups were embedded at a spacing of $150 \mathrm{~mm}$. The Fe-SMA rebars used in the experiment had a square cross-section of $10 \mathrm{~mm} \times 10 \mathrm{~mm}$. Thread fasteners of $100 \mathrm{~mm}$ length for bolting were machined at both ends of the Fe-SMA rebars to prevent slippage during the experiment, as shown in Figure 2. The Fe-SMA rebars were stretched to a targeted prestrain of 0.04 by a horizontal hydraulic jack. After completing pretension of the Fe-SMA rebars, the U-shaped stirrups and Fe-SMA rebars were assembled and placed in concrete molds. Ready-mix concrete from a local batch plant was poured in the concrete molds, and the concrete beams were demolded three days after casting. The concrete beams were cured for 28 days, and then the Fe-SMA rebars were activated. The cross-sectional areas of Fe-SMA rebars $\left(200 \mathrm{~mm}^{2}, 300 \mathrm{~mm}^{2}, 400 \mathrm{~mm}^{2}\right.$, and $\left.500 \mathrm{~mm}^{2}\right)$, the activation of the Fe-SMA rebars, and usage of an anchoring device were considered as variables for the experiment, which are given in Table 1. The variable denoted as "BE" in Table 1 refers to "beam" and the Arabic number is the number of Fe-SMA rebars. In addition, the letters " $\mathrm{A}$ ", " $\mathrm{N}$ ", and " $\mathrm{R}$ " denote activation of Fe-SMA, no activation of Fe-SMA, and reactivation of Fe-SMA rebars. The last letter of " $\mathrm{A}$ " or " $\mathrm{N}$ " indicates whether or not the anchoring device is used.

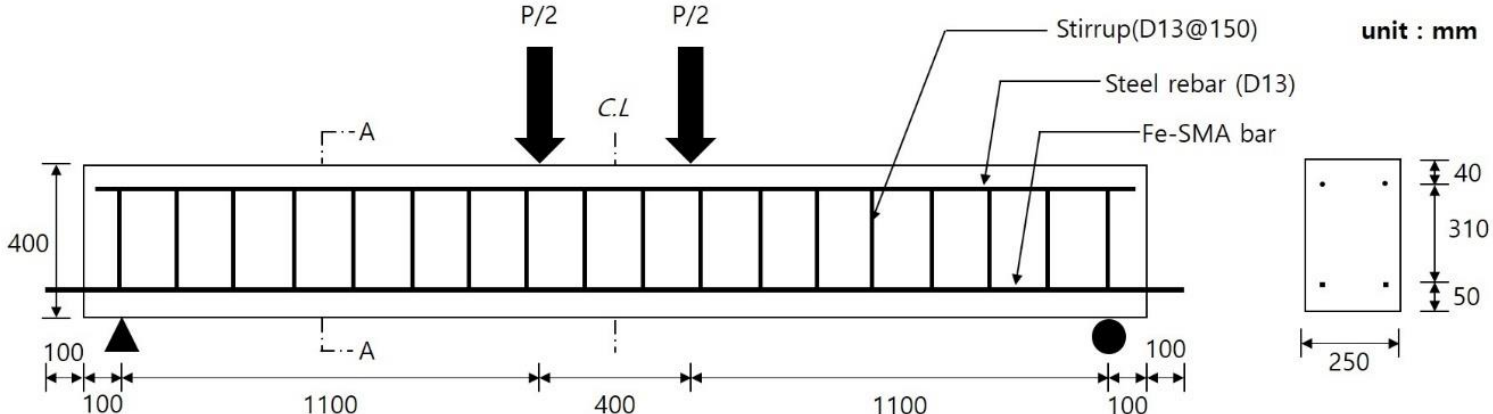

(a)

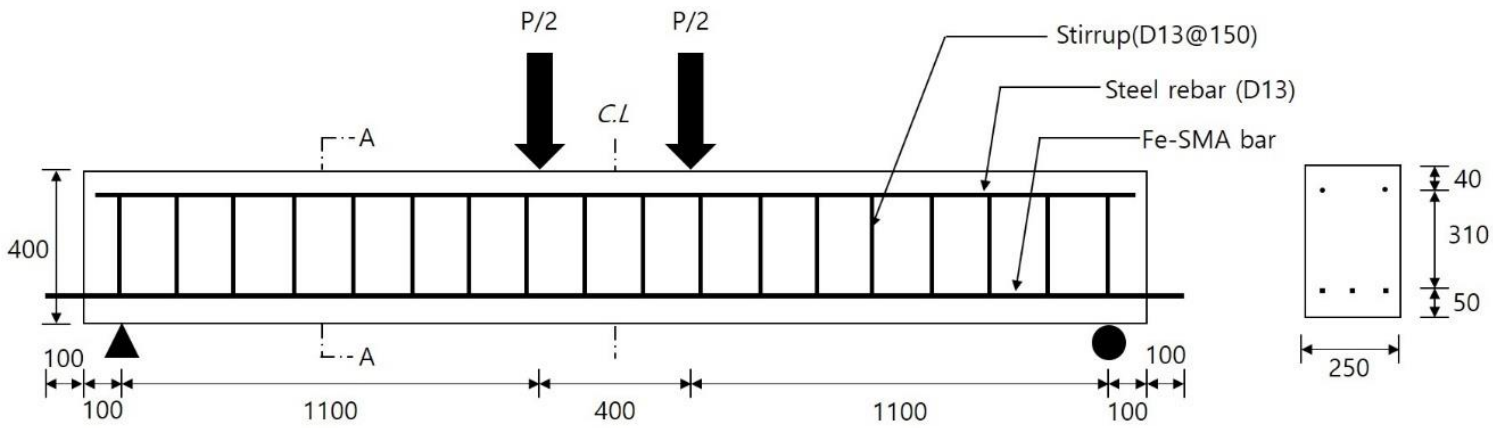

(b)

Figure 1. Cont. 


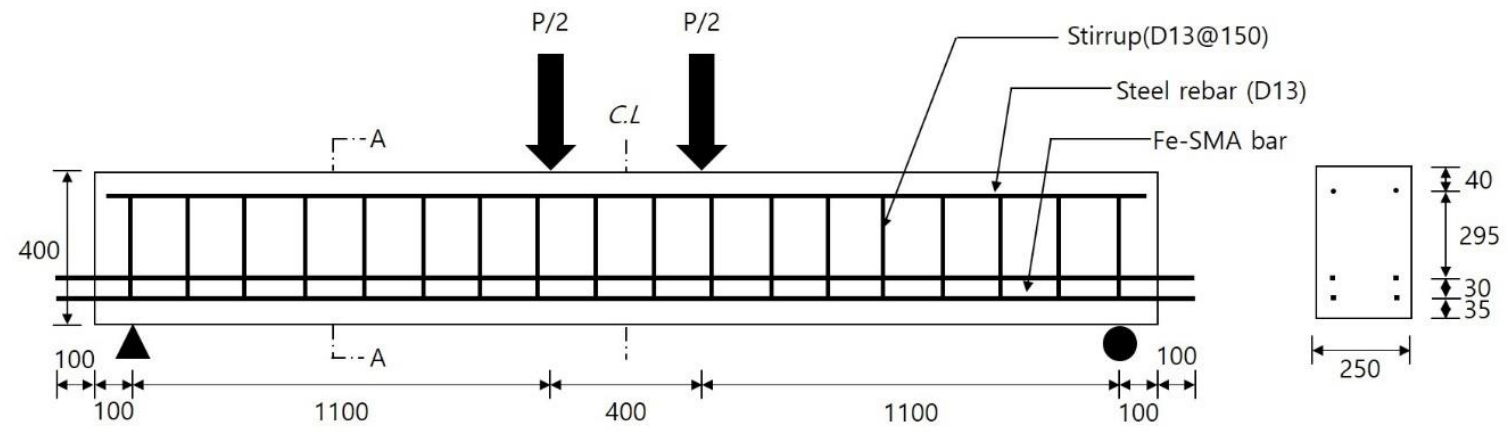

(c)

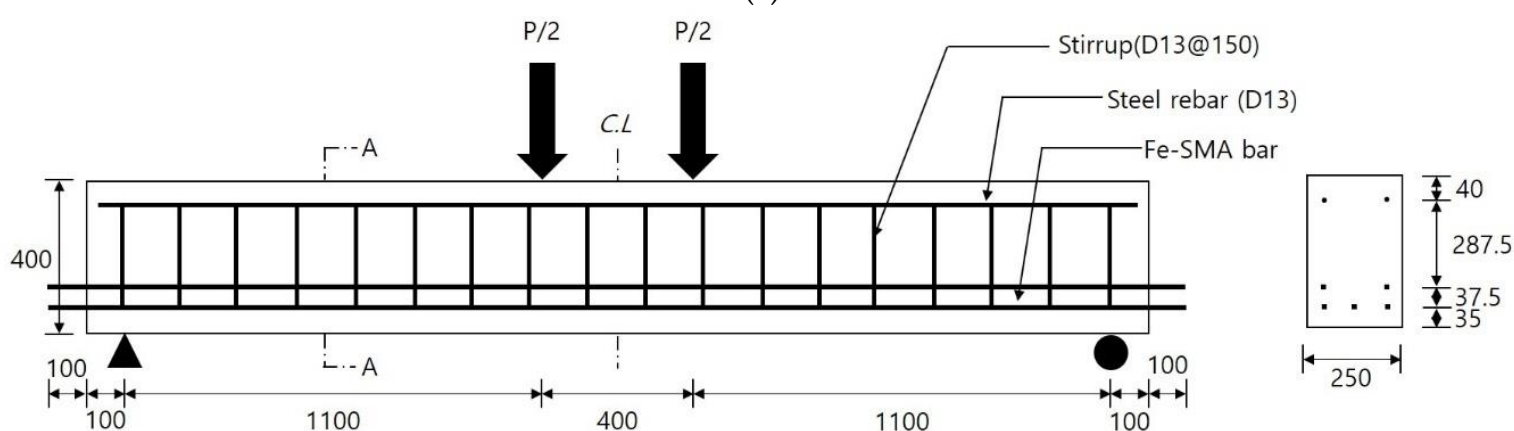

(d)

Figure 1. Test beam specimens. (a) Beams BE-2N-A and BE-2A-A. (b) Beams BE-3N-A, BE-3A-A, BE-3R-A, and BE-3A-N. (c) Beams BE-4N-A and BE-4A-A. (d) Beams BE-5N-A and BE-5A-A.

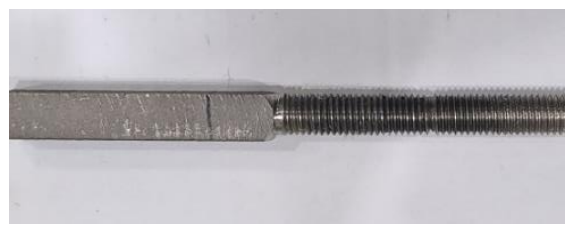

Figure 2. Screw tap.

Table 1. Test variables.

\begin{tabular}{|c|c|c|c|}
\hline Specimen & $\begin{array}{c}\text { Area of Fe-SMA } \\
\text { Rebars }\left(\mathrm{mm}^{2}\right)\end{array}$ & Activation & Anchorage \\
\hline BE-2N-A & \multirow{3}{*}{200} & Nonactivation & \multirow[b]{6}{*}{ Non-anchorage } \\
\hline BE-2A-A & & Activation & \\
\hline BE-3N-A & & Nonactivation & \\
\hline BE-3A-A & \multirow{3}{*}{300} & & \\
\hline BE-3R-A & & Activation & \\
\hline BE-3A-N & & & \\
\hline BE-4A-A & \multirow{2}{*}{400} & Nonactivation & \multirow{4}{*}{ Anchorage } \\
\hline BE-4A-A & & Activation & \\
\hline BE-5A-A & \multirow{2}{*}{500} & Nonactivation & \\
\hline BE-5A-A & & Activation & \\
\hline
\end{tabular}

\subsection{Materials}

The design compressive strength of concrete used for the specimens was $40 \mathrm{MPa}$, and Table 2 shows the mix design for this concrete. "W", "C", "S", "G", and "Ad" in Table 2 refer to water, cement, sand, gravel, and water-reducing admixture, respectively. Maximum gravel size of $25 \mathrm{~mm}$, an S/a ratio of $47 \%$, and a water-to-cement ratio (W/C) of 30.7\% were considered to produce the concrete material. To evaluate the compressive strength 
of the concrete, five concrete cylinder specimens with sizes of $\varnothing 100 \mathrm{~mm} \times 200 \mathrm{~mm}$ were simultaneously cast. The concrete beam and cylinder specimens were cured and demolded under the identical surrounding conditions. The average compressive strength of the concrete was 46.2 MPa in accordance with the American Standard for Test and Material (ASTM) C39/39M [24].

Table 2. Mixing properties of the concrete.

\begin{tabular}{|c|c|c|c|c|c|c|c|c|}
\hline \multirow{2}{*}{$\begin{array}{l}\text { Slump } \\
(\mathrm{cm})\end{array}$} & \multirow{2}{*}{$\begin{array}{c}\text { Air Content } \\
(\%)\end{array}$} & \multirow{2}{*}{$\begin{array}{l}\text { W/B } \\
(\%)\end{array}$} & \multirow{2}{*}{$\begin{array}{l}\text { S/a } \\
(\%)\end{array}$} & \multicolumn{5}{|c|}{ Weight per Unit Volume $\left(\mathrm{kg} / \mathrm{m}^{3}\right)$} \\
\hline & & & & $\mathbf{W}$ & $\mathrm{C}$ & S & G & AD \\
\hline 12 & 4.5 & 30.7 & 47 & 192 & 625 & 684 & 780 & 4.38 \\
\hline
\end{tabular}

The nominal diameter of the steel rebars used as compression rebars and shear stirrups was $13 \mathrm{~mm}$. The modulus of elasticity and the yielding stress of the steel rebars were $200 \mathrm{GPa}$ and $462 \mathrm{MPa}$, and their yielding strain was $17.1 \%$. Table 3 shows the material properties of the steel rebars used.

Table 3. Material properties of the steel rebars.

\begin{tabular}{ccccccc}
\hline Standard No. & $\begin{array}{c}\text { Nominal Diameter } \\
(\mathbf{m m})\end{array}$ & $\begin{array}{c}\text { Nominal Area } \\
\left(\mathbf{m m}^{\mathbf{2}}\right)\end{array}$ & $\begin{array}{c}\text { Young's Modulus } \\
\mathbf{( G P a )}\end{array}$ & $\begin{array}{c}\text { Yield Strength } \\
(\mathbf{M P a})\end{array}$ & $\begin{array}{c}\text { Ultimate Strength } \\
\mathbf{( M P a})\end{array}$ & $\begin{array}{c}\text { Elongation } \\
\mathbf{( \% )}\end{array}$ \\
\hline D13 & 12.6 & 126.7 & 200 & 462 & 540 & 17.1 \\
\hline
\end{tabular}

Figure 3 represents the Fe-SMA rebars used in this paper. The chemical composition of Fe-SMA rebar is Fe-17Mn-5Si-5Cr-0.3C-1Ti. The Fe-SMA rebars were manufactured using a vacuum induction melting pot. First, all components of Fe-SMA rebars were placed into the vacuum induction melting pot to make a $1000 \mathrm{~kg}$ ingot. The ingot was heat-treated at $1250{ }^{\circ} \mathrm{C}$ for six hours to homogenize the alloy and then forged into a plate with a thickness of $10 \mathrm{~mm}$ by hydraulic stamping. The Fe-SMA plates were then cut by a water jet into rebars with $10 \mathrm{~mm}$ square sections. Direct tensile tests were performed to confirm the mechanical properties of the Fe-SMA rebars. The dimensions of the test samples had a length of $200 \mathrm{~mm}$ and a width of $10 \mathrm{~mm}$ with a thickness of $2.5 \mathrm{~mm}$, respectively. The direct tensile tests were performed with a displacement control at a loading rate of $0.5 \mathrm{~mm} / \mathrm{min}$ in a universal testing machine (UTM). The strains were measured by strain gauges attached in the middle of the specimens, and the measured data were collected at one-second intervals by a data acquisition system (DAQ). Figure 4 shows a typical stress-strain curve of the Fe-SMA rebars according to the results of the direct tensile tests. The modulus of elasticity, the ultimate stress, and the corresponding ultimate strain were determined as $201 \mathrm{GPa}$, $1035 \mathrm{MPa}$, and 20\%, respectively. A special characteristic of the Fe-SMA material is that it did not show a distinguished yielding point, whereas a clear yield point appeared in the direct tensile tests of normal steel rebars. Therefore, to determine the yielding stress of the Fe-SMA rebars, the $0.2 \%$ offset method was employed, resulting in an average yielding stress of $451 \mathrm{MPa}$.

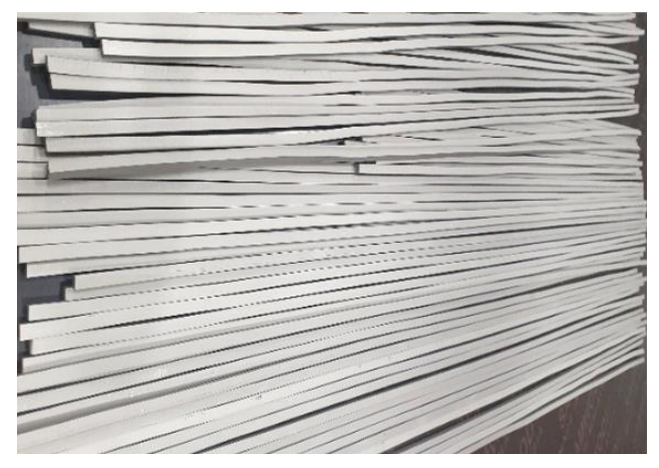

Figure 3. Fe-SMA rebars in this study. 


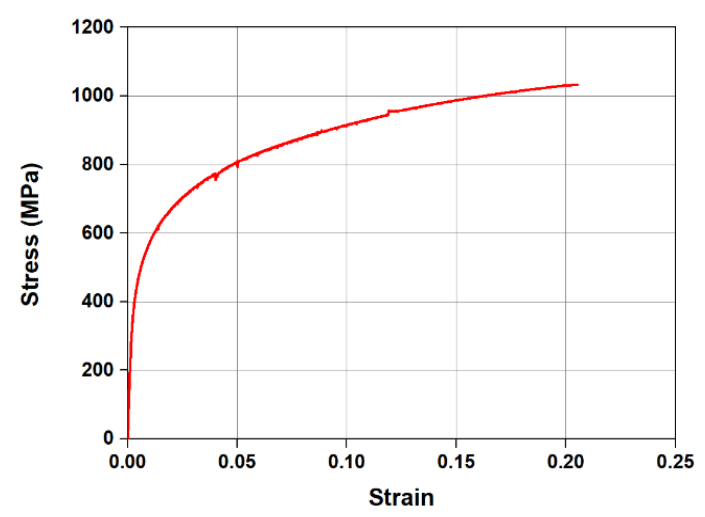

Figure 4. Typical stress-strain relationship of the Fe-SMA rebars.

The recovery stress of the Fe-SMA bars was evaluated using the same samples as those for the direct tensile tests. Lee et al. [25] reported that Fe-SMA strips prestrained to over $4 \%$ had reduced corrosion resistance. Moreover, with regard to heating temperature exceeding $160{ }^{\circ} \mathrm{C}$, Park et al. [26] reported that ettringite at the interface between cement and gravel was melted, and Yeon [27] reported that internal cracks surrounding the Fe-SMA rebars occurred due to the evaporated internal moisture. From those studies related to the mechanical behaviors of Fe-SMA rebars, the prestrain and heating temperature were, respectively, decided as $4 \%$ and $160{ }^{\circ} \mathrm{C}$. The Fe-SMA rebars were stretched to the targeted prestrain level using a $100 \mathrm{kN}$ capacity UTM by displacement control at a loading rate of $0.25 \mathrm{~mm} / \mathrm{min}$, and the tension was reduced to 0 by the same loading speed after the strains of the Fe-SMA rebars reached the targeted strain level. To prevent buckling behavior of the Fe-SMA rebars by heating expansion, a pretensile stress of $50 \mathrm{MPa}$ was applied. After the pretension, both ends of the samples were fixed by the hydraulic wedges of the UTM. The Fe-SMA rebars were heated up to a designated transformation temperature by the electric resistance heating generated from a current of $2 \mathrm{~A} / \mathrm{mm}^{2}$. The surface temperatures of the rebars were measured by a noncontacted infrared thermal sensor and were recorded at one-second intervals using a DAQ, as shown in Figure 5. When the surface temperature reached the designated transformation heating temperature of $160^{\circ} \mathrm{C}$, the electricity was disconnected, and the specimens were cooled to the ambient temperature. Figure 6 shows a typical temperature-recovery stress relationship of the Fe-SMA rebars during heating and cooling. As shown in Figure 6, the recovery stress somewhat decreased at the initial heating temperature of $35^{\circ} \mathrm{C}$ due to thermal expansion and thereafter increased steadily with heating. The recovery stress of $335 \mathrm{MPa}$ occurred when the Fe-SMA rebars were cooled to the ambient temperature. Figure 7 shows a typical stress-strain curve of the rebars after the tension was removed. The stress-strain curves were drawn by the following steps: the stress was reduced while removing the tension; the recovery stress occurred, as shown by the vertical straight line, at the strain of 0.0327 ; and the stress was reduced to the zero upon removing the tension generated by the recovery stress, indicated by the red line in Figure 7 . Specifically, at the red line, the modulus of elasticity of the Fe-SMA rebars was measured as $152 \mathrm{GPa}$. 


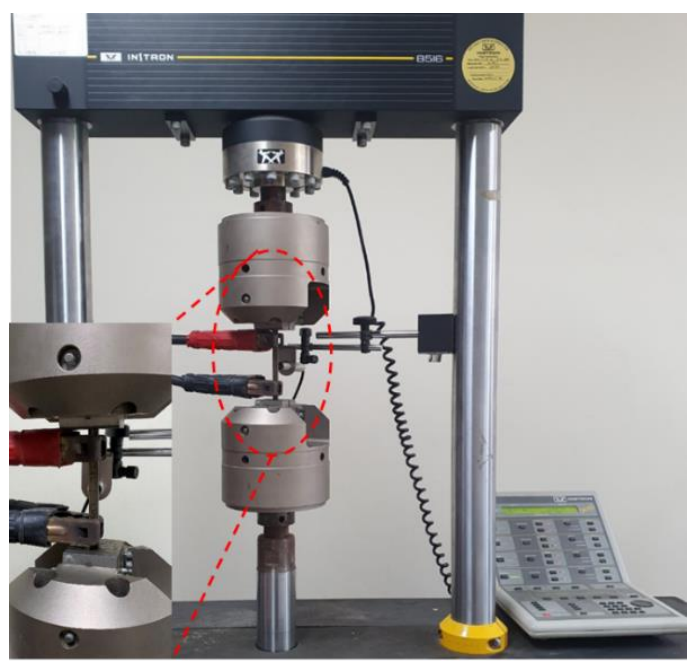

Figure 5. Test setup for Fe-SMA activation.

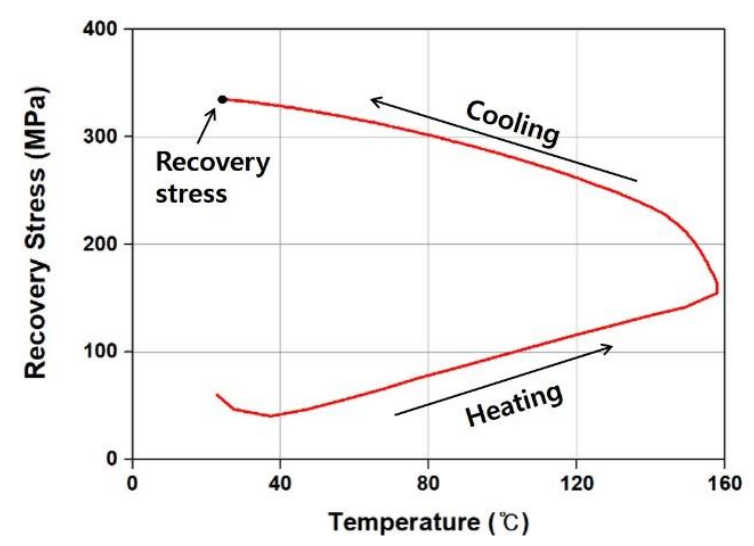

Figure 6. Typical recovery stress-temperature relationship of the $4 \%$ prestrained Fe-SMA rebars.

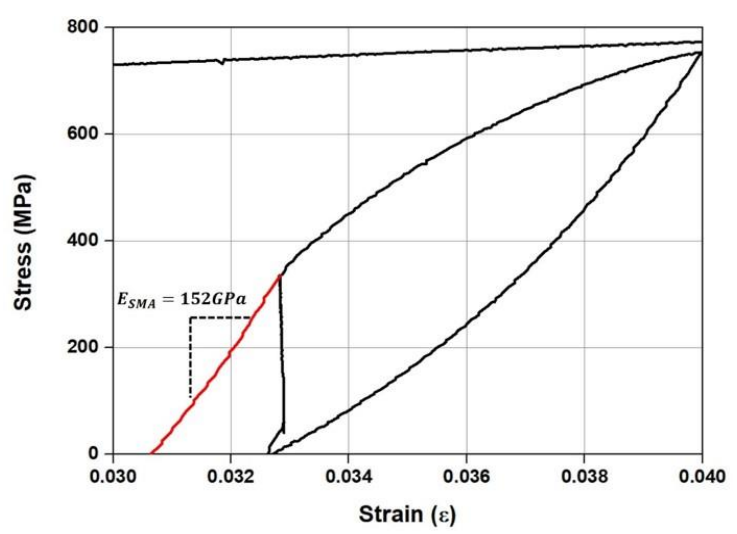

Figure 7. Typical stress-strain relationship of the $4 \%$ prestrained Fe-SMA rebars after the activation test.

\subsection{Test Setup}

Figure 8 shows the configuration of the system for activation of the Fe-SMA rebars. As mentioned before, the beam specimens were laid on the test frame with the net length of $2600 \mathrm{~mm}$. The Fe-SMA rebars embedded in the beam specimens were activated by the resistance heating with an electrical voltage of $5 \mathrm{~A} / \mathrm{mm}^{2}$. As shown in Figure 8 , the Fe-SMA rebars' temperatures were measured using a noncontact infrared thermal sensor. From a preliminary test for the material heating temperature, the central cross-section temperature of the Fe-SMA rebar reached $160{ }^{\circ} \mathrm{C}$ when the end of the threaded Fe-SMA 
rebar was heated to $440{ }^{\circ} \mathrm{C}$. When the surface temperatures of the Fe-SMA rebars with and without spiral threads reached $440^{\circ} \mathrm{C}$ and $160^{\circ} \mathrm{C}$, respectively, the power supply was turned off. The camber generated during the activation of the Fe-SMA rebars was measured by a linear-variable displacement transducer (LVDT) with a range of $10 \mathrm{~mm}$ at the central bottom of the beam specimens. The data measured by the thermocouples and LVDTs were collected and stored at one-second intervals using a DAQ. After the camber of the beam specimens became stable due to activation of the Fe-SMA rebars, four-point bending tests were carried out using a hydraulic actuator with a capacity of $2000 \mathrm{kN}$ to evaluate the flexural behaviors of the concrete beams reinforced with the Fe-SMA rebars. As shown in Figure 1, the spacing between the loading points of the beam specimen was $400 \mathrm{~mm}$, with each point located $200 \mathrm{~mm}$ from the center. The four-point bending tests were carried out by using displacement control at a loading rate of $3 \mathrm{~mm} / \mathrm{min}$. Displacements were measured by using LVDTs at the central bottom of the beam specimens. Initial cracks and crack propagations were indicated on the surface of the beam specimens. Figure 9 shows the test setup.

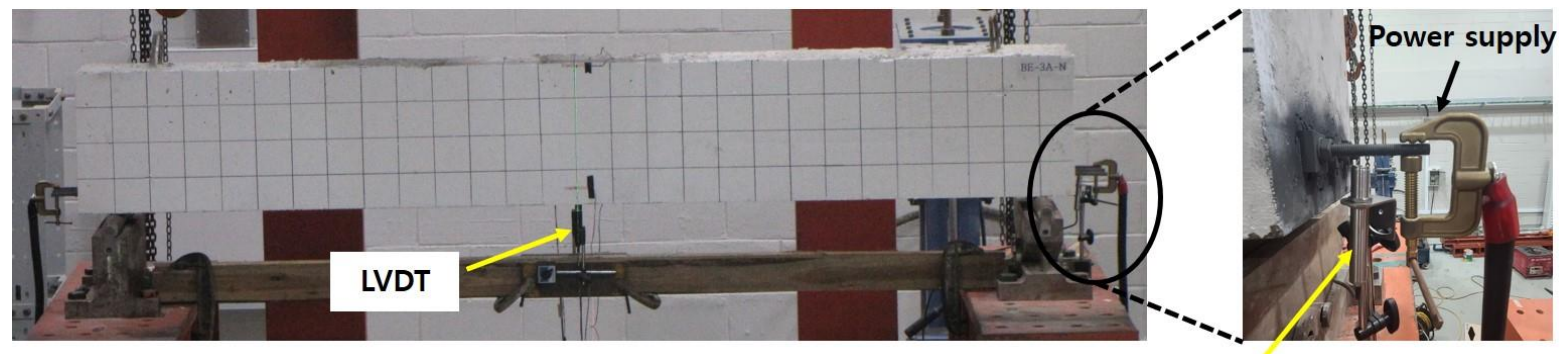

Infrared thermometer

Figure 8. Overview of the activation system.

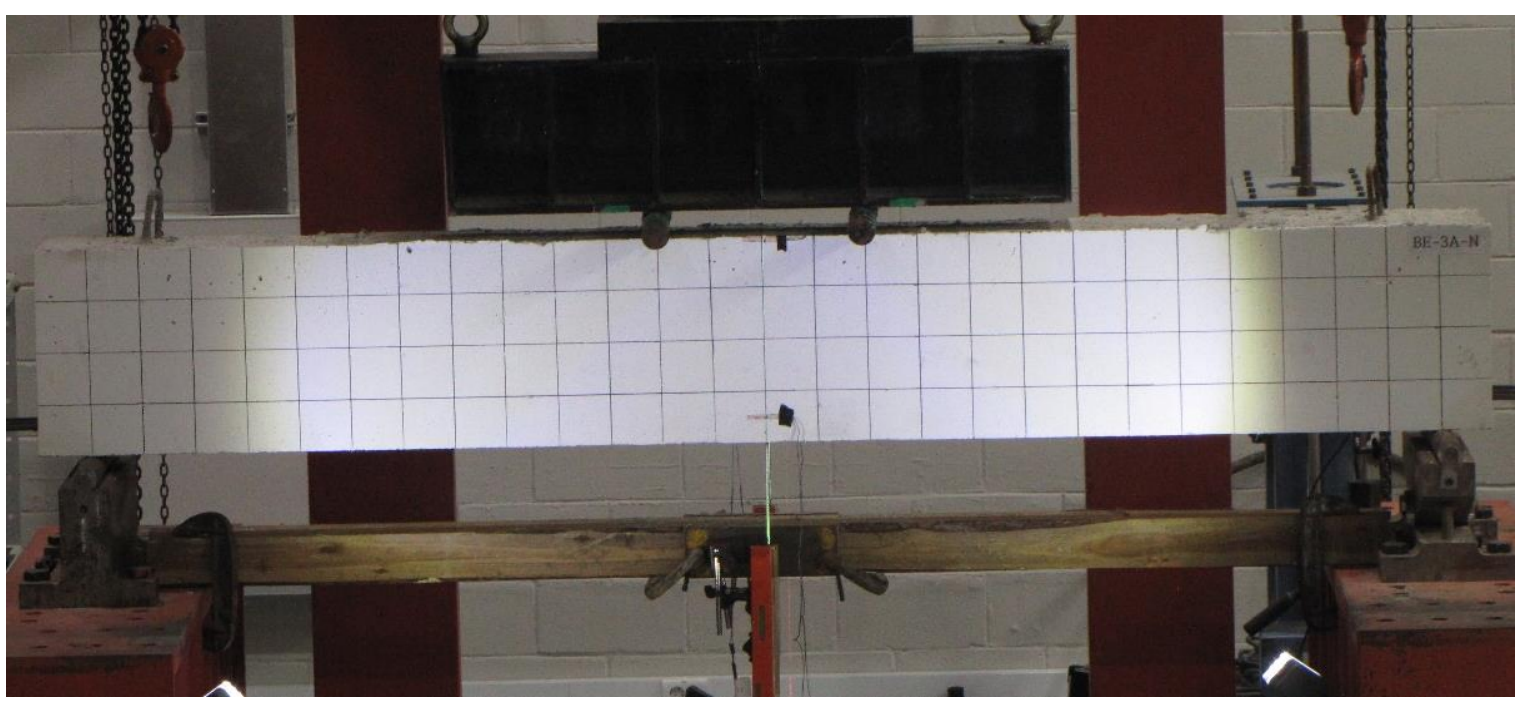

Figure 9. Test setup.

\section{Experiment Results and Discussion}

\subsection{Activation of the Fe-SMA Rebars}

Based on the results of the activation of the Fe-SMA rebars, Table 4 shows a comparison of the experimental and theoretical cambers at the centers of the specimens, and Figure 10 shows the time-displacement curves at the centers of the beam specimens. As shown in Figure 10, the time-displacement curves are clearly divided into two stages. In the first stage of the activation, downward displacements caused by the thermal expansion of the 
Fe-SMA rebars were observed. However, as the rebars were continuously activated, the eccentric compressive forces acting in the concrete tension zones gradually recovered the downward deformations and eventually induced upward deformations. The maximum cambers of beams BE-2A-A, BE-3A-A, BE-4A-A, and BE-5A-A due to the activation of the Fe-SMA bars were $0.140 \mathrm{~mm}, 0.206 \mathrm{~mm}, 0.267 \mathrm{~mm}$, and $0.420 \mathrm{~mm}$, respectively. As the cross-sectional area of the Fe-SMA rebars increased by $100 \mathrm{~mm}^{2}$, the camber increased by $0.093 \mathrm{~mm}$ on average. This is because as the area of the Fe-SMA bars increased, the eccentric compressive forces increased. Figure 11 shows a comparison of the time-displacement curves at the centers of the beam specimens by activating the Fe-SMA rebars for beam BE-3A-N without using an anchor and beam BE-3A-A by using an anchor. As shown in Figure 11, the upward displacement of $0.204 \mathrm{~mm}$ for beam BE-3A-A was slightly different from that for beam BE-3A-N by less than $1 \%$. As mentioned before, beams BE-3A-A and BE$3 \mathrm{~A}-\mathrm{N}$ depended on the use of the anchoring device at the ends of the Fe-SMA rebars. It was assumed that the beam specimens remain elastic, and the cambers in the beam specimens due to the recovery stress of the Fe-SMA rebars can then be theoretically calculated using Equations (1)-(3).

Table 4. Summary of the upward midspan displacements.

\begin{tabular}{cccc}
\hline Specimen & $\delta_{\text {upward,exp }}(\mathbf{m m})$ & $\delta_{\text {upward,theory }}(\mathbf{m m})$ & $\delta_{\text {upward,exp }} / \delta_{\text {upward,theory }}$ \\
\hline BE-2A-A & 0.140 & 0.193 & 0.725 \\
BE-3A-A & 0.206 & 0.287 & 0.718 \\
BE-4A-A & 0.297 & 0.379 & 0.784 \\
BE-5A-A & 0.420 & 0.469 & 0.896 \\
Average & & & 0.781 \\
\hline
\end{tabular}

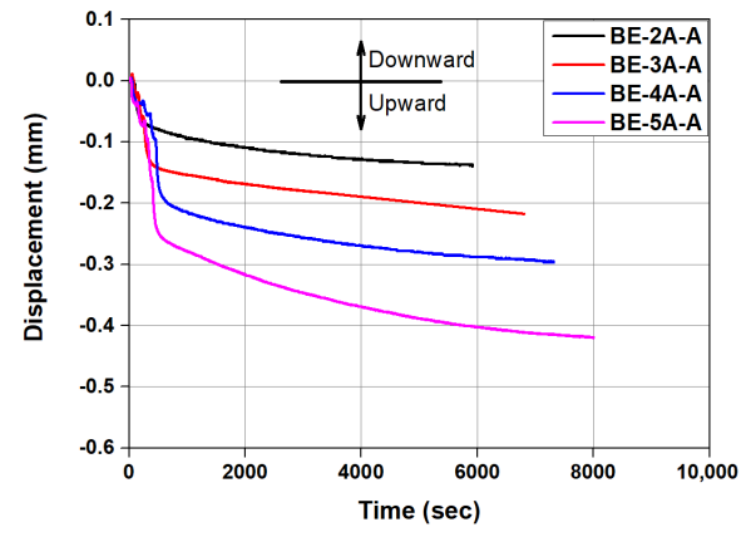

Figure 10. Time-displacement relationships for Fe-SMA bars with different cross-sectional areas.

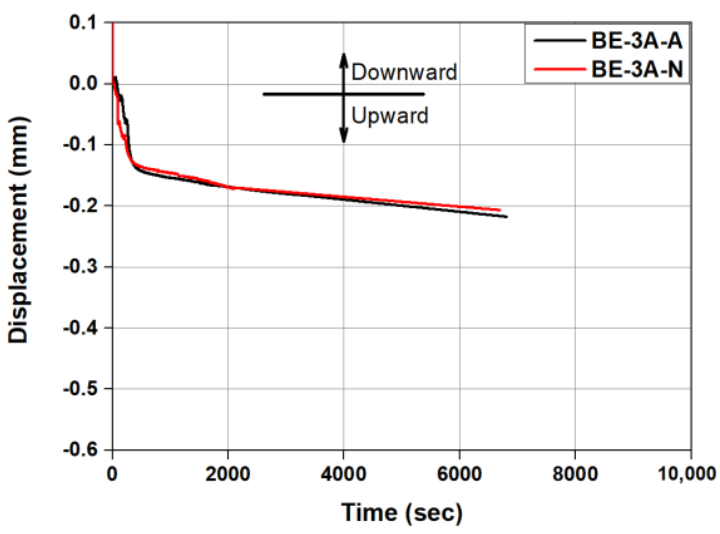

Figure 11. Time-displacement relationships of beams BE-3A-A and BE-3A-N. 


$$
\begin{gathered}
\delta_{\text {upward }}=\left(M_{\text {rec }} L^{2}\right) /\left(8 E_{c} I_{g}\right) \\
M_{\text {rec }}=P_{\text {rec }} e \\
P_{\text {rec }}=A_{\text {sma }} f_{\text {rec }}
\end{gathered}
$$

where $\delta_{\text {upward }}$ is the camber, $M_{\text {rec }}$ is the moment caused by the eccentric compressive force generated by the recovery stress of the Fe-SMA rebars, $P_{r e c}$ is the compressive force generated by the recovery stress of the Fe-SMA rebars, $e$ is the eccentric distance from the centroid line, $A_{s m a}$ is the area of the Fe-SMA rebars, and $f_{r e c}$ is the recovery stress of the Fe-SMA rebars. In addition, $I_{g}$ is the moment of inertia of the beam cross-section and $E_{c}$ is the concrete modulus of elasticity. $I_{g}$ and $e$ are calculated using the transformed section method and the parallel axis theorem, as expressed in Equations (4)-(10). $E_{c}$ is calculated from Equation (11) in accordance with ACI 318.

$$
\begin{gathered}
n_{s}=\frac{E_{s}}{E_{c}}, n_{s m a}=\frac{E_{s m a}}{E_{c}} \\
y_{t}=\frac{0.5 b h^{2}+\left(n_{s}-1\right) A_{s} d^{\prime}+\left(n_{s m a}-1\right) A_{s m a} d}{b h+\left(n_{s}-1\right) A_{s}+\left(n_{s m a}-1\right) A_{s m a}} \\
e=d-y_{t} \\
I_{c}=b h^{3} / 12+b h\left(0.5 h-y_{t}\right)^{2} \\
I_{s}=\left(n_{s}-1\right) A_{s}\left(y_{t}-d^{\prime}\right)^{2} \\
I_{s m a}=\left(n_{s m a}-1\right) A_{s m a}\left(y_{t}-d\right)^{2} \\
I_{g}=I_{c}+I_{s}+I_{s m a} \\
E_{c}=4700 \sqrt{f_{c k}}
\end{gathered}
$$

where $E_{s}$ denotes the modulus of elasticity of reinforcement and $E_{s m a}$ is the modulus of elasticity of the Fe-SMA rebars without tension after activation, respectively. $n_{S}$ and $n_{\text {sma }}$ denote the elastic moduli of the reinforcement and the Fe-SMA rebars, respectively. In addition, $b, h, d$, and $d^{\prime}$ denote the width, height, effective depth, and depth of the compression reinforcement, respectively, and $y_{t}$ and $A_{s}$ are the depth of the neutral axis and the cross-sectional area of the reinforcement. $I_{c}, I_{s}$, and $I_{s m a}$ denote the effective second moments of area for the concrete, compression reinforcement, and Fe-SMA rebars.

Figure 12 shows a comparison of the cambers from the theoretical and experiment results. In Table 4, the experimental camber was $21.9 \%$ smaller than the theoretical value, resulting in an average ratio of the theoretical to experimental results of 0.781 . This is because the Fe-SMA rebars embedded inside the concrete beam specimens were activated by the heat of hydration during curing of the beam specimens. In general, concrete material with compressive strength above $40 \mathrm{MPa}$ is categorized as high-strength concrete, and it has relatively higher heat of hydration due to the cement volume being larger than that of normal concrete. The compressive strength of the concrete in this study was $46.2 \mathrm{MPa}$, and higher heat of hydration might have been generated during concrete curing.

With these results, it is noted that a method to control the heat of hydration during the concrete curing should be considered in the step of casting the concrete specimens using the Fe-SMA rebars. 


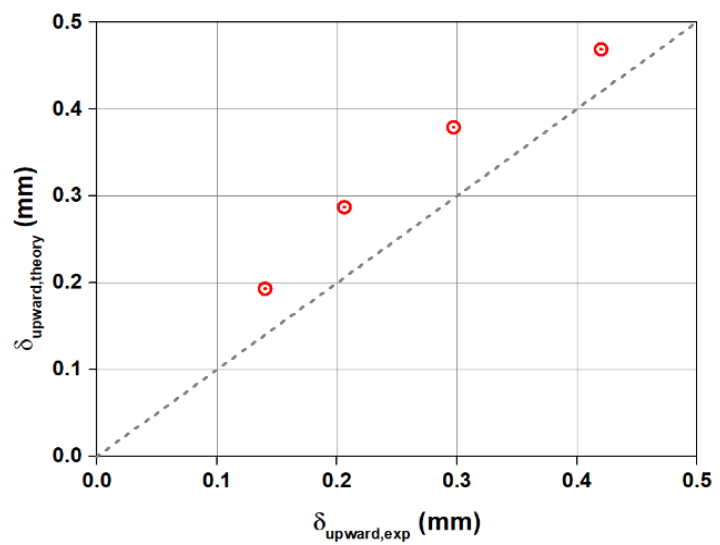

Figure 12. Comparison of $\delta_{\text {upward,exp }}$ and $\delta_{\text {upward,theory }}$.

\subsection{Failure Mode}

Figure 13 shows the crack patterns on the beam specimens, and the experiment results are given in Table 5. In the initial loading stage, cracks developed at the bottom of all central beam specimens. The vertical displacement at the central bottom of the specimens increased with the increasing load, resulting in cracks propagating to the compression zone of the beam specimens, and failure occurred in the compression zone with the concrete being crushed. As shown in Figure 13, the number of flexural cracks in beams BE-2N-A, BE-3N-A, BE-4N-A, and BE-5N-A, where the Fe-SMA rebars were not activated, was 6, 10, 12 , and 12 , respectively. In the specimens where Fe-SMA was activated, an increase in the number of flexural cracks was observed as the amount of the Fe-SMA rebars increased. As for general RC members, it was found that more flexural cracks occurred in the concrete members reinforced with Fe-SMA rebars as the amount of Fe-SMA increased.

As shown in Figure 13a, four deflection cracks with the widths greater than $1 \mathrm{~mm}$ developed at the central bottom of beam BE-2N-A, where the Fe-SMA rebars were not activated. On the other hand, beam BE-2A-A with the activated Fe-SMA rebars had three major cracks with the width greater than $1 \mathrm{~mm}$. The difference between beams BE-2A-A and BE-2N-A was the activation of the Fe-SMA rebars. Comparing the crack configurations from Figure 13a-h, the activation of the Fe-SMA rebars reduced the crack occurrences by about $60 \%$, compared to the beams where the Fe-SMA rebars were not activated. This phenomenon might be attributed to the recovery stress of the Fe-SMA rebars caused by the SME acting on the beam specimen in the tension zone as the compressive force.

\subsection{Load-Deflection Relationships}

\subsubsection{Effect of Fe-SMA Activation}

Figure 14 shows a comparison of the load-deflection relationships between beam with the nonactivated Fe-SMA rebars and beam with the activated Fe-SMA rebars. As shown in Figure 14a, the initial cracks occurred at the loads of $42.31 \mathrm{kN}$ and $64.46 \mathrm{kN}$ for beams $\mathrm{BE}-2 \mathrm{~N}-\mathrm{A}$ and $\mathrm{BE}-2 \mathrm{~A}-\mathrm{A}$, respectively, and beam BE-2A-A had a higher initial cracking load by $47.6 \%$. The initial cracking loads of beams BE-3A-A, BE-4A-A, and BE-5A-A increased by $63.0 \%, 76.9 \%$, and $112.8 \%$, respectively, compared to the test specimens with the nonactivated Fe-SMA rebars. This is because the compressive strength generated by the recovery stress of the Fe-SMA rebars in the tension zone of the beam specimens increased the crack development resistance. However, the ultimate loads of the beam specimens that had identical areas of the Fe-SMA rebars were slightly different, within a range of variations from $0.38 \%$ to $2.86 \%$, regardless of whether the rebars were activated or not. These results indicate that the compressive strength introduced to the compression zone of the beam specimens did not have a significant impact in the ultimate load stage, similar to the PSC members. In other words, the recovery stress of the Fe-SMA rebars can play a significant role in improving usability by controlling the initial cracks. 


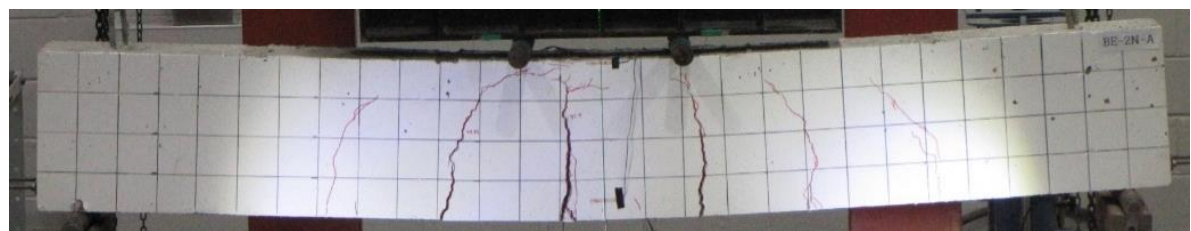

(a)

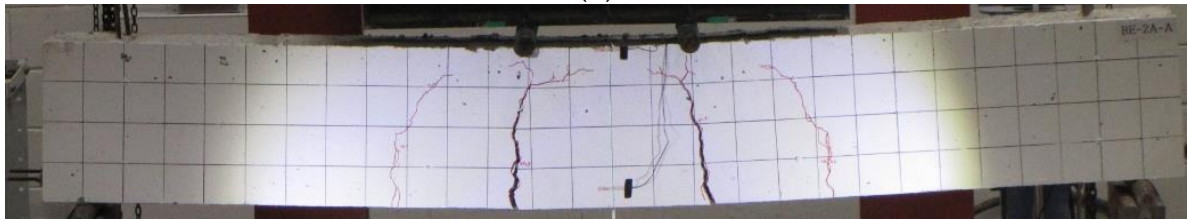

(b)

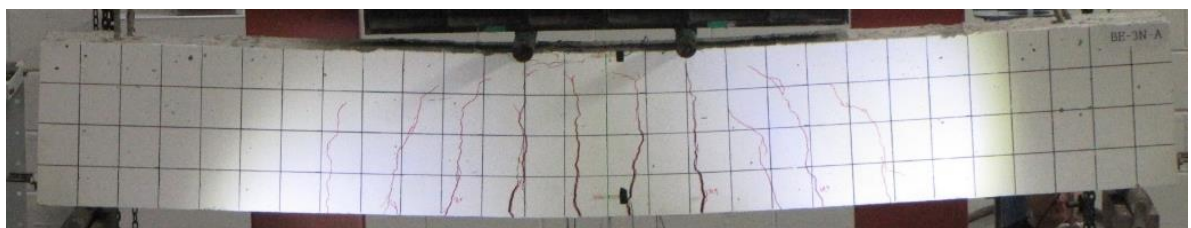

(c)

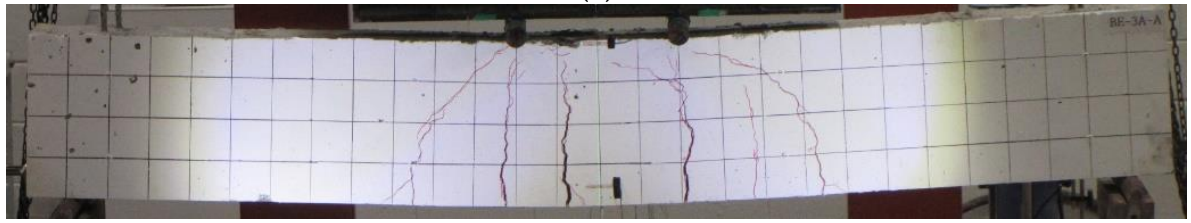

(d)

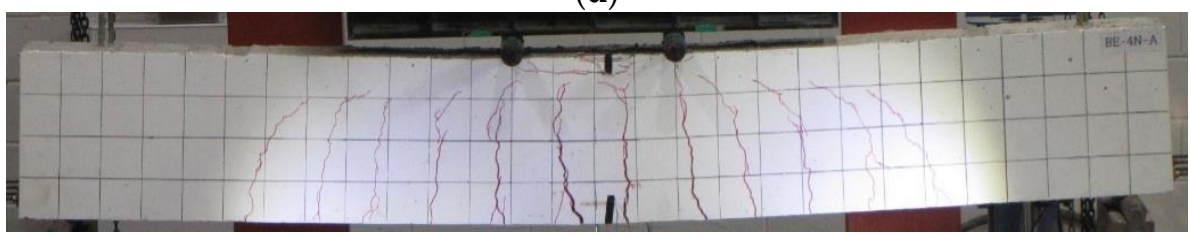

(e)

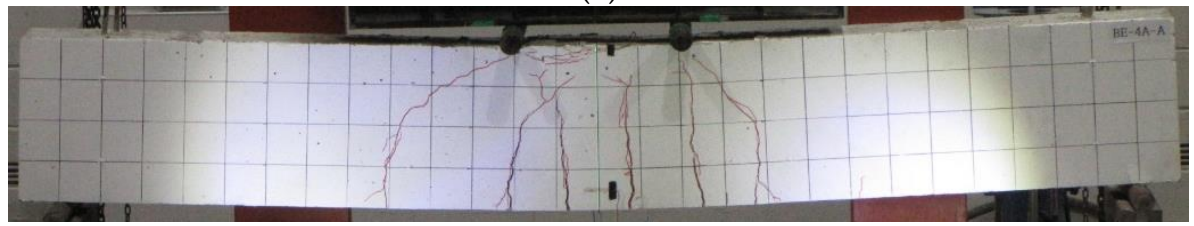

(f)

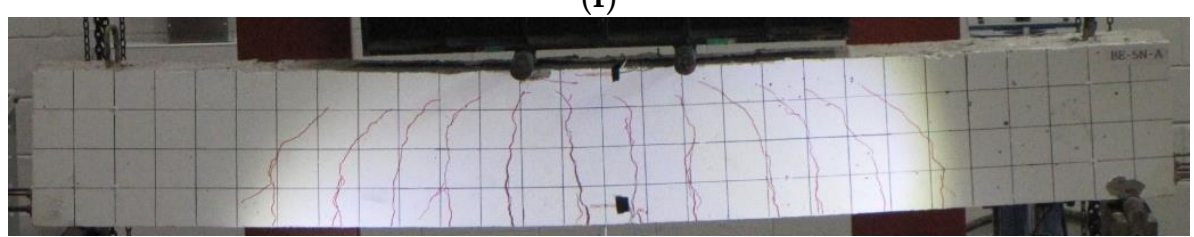

(g)

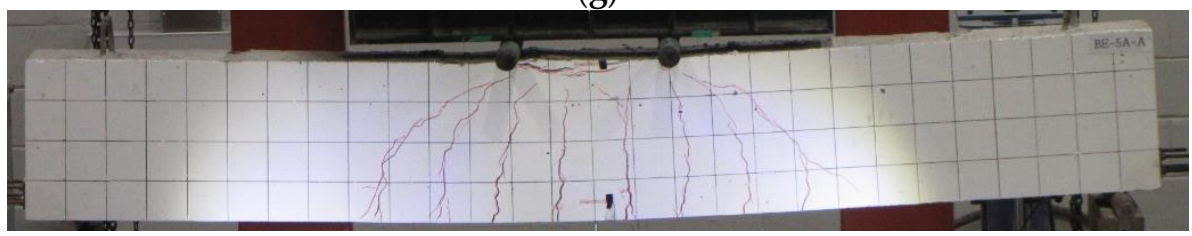

(h)

Figure 13. Failure modes of the beam specimens. (a) Beam BE-2N-A. (b) Beam BE-2A-A. (c) Beam BE-3N-A. (d) Beam BE-3A-A. (e) Beam BE-4N-A. (f) Beam BE-4A-A. (g) Beam BE-5N-A. (h) Beam BE-5A-A. 
Table 5. Summary of the test results.

\begin{tabular}{cccccc}
\hline \multirow{2}{*}{ Specimen } & \multicolumn{2}{c}{ Initial Crack } & \multicolumn{2}{c}{ Ultimate State } & Failure \\
\cline { 2 - 5 } & $\begin{array}{c}\text { Deflection } \\
(\mathbf{m m})\end{array}$ & $\begin{array}{c}\text { Load } \\
\mathbf{( k N )}\end{array}$ & $\begin{array}{c}\text { Deflection } \\
\mathbf{( m \mathbf { m } )}\end{array}$ & $\begin{array}{c}\text { Load } \\
\mathbf{( k N )}\end{array}$ & $\begin{array}{c}\text { Mode } \\
\text { BE-2N-A }\end{array}$ \\
\hline 0.71 & 42.31 & 43.82 & 122.77 & \\
BE-2A-A & 1.45 & 62.46 & 39.47 & 119.26 & \\
BE-3N-A & 0.96 & 50.01 & 43.33 & 165.9 & \\
BE-3A-A & 1.25 & 81.51 & 38.41 & 166.53 & \\
BE-3R-A & 1.2 & 81.38 & 37.11 & 159.44 & Flexural \\
BE-3A-N & 0.95 & 80.14 & 42.62 & 165.64 & \\
BE-4A-A & 0.95 & 53.92 & 38.71 & 203.14 & \\
BE-4A-A & 1.81 & 95.42 & 40.00 & 205.86 & \\
BE-5A-A & 1.03 & 50.74 & 28.43 & 249.94 & \\
BE-5A-A & 1.89 & 107.98 & 35.00 & 246.28 & \\
\hline
\end{tabular}

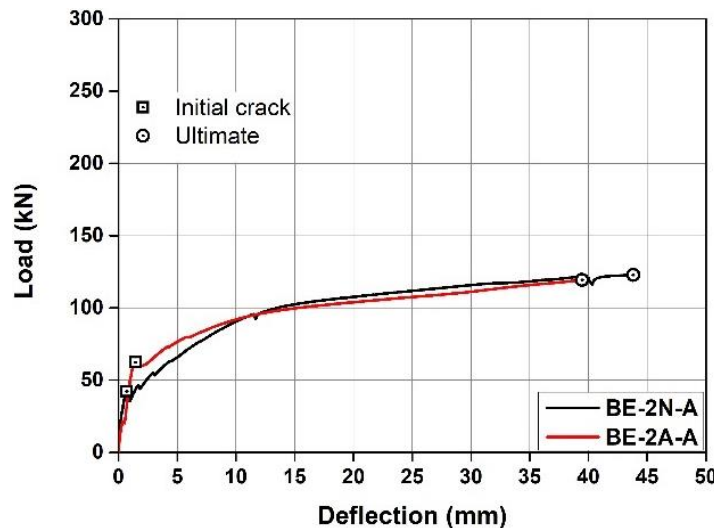

(a)

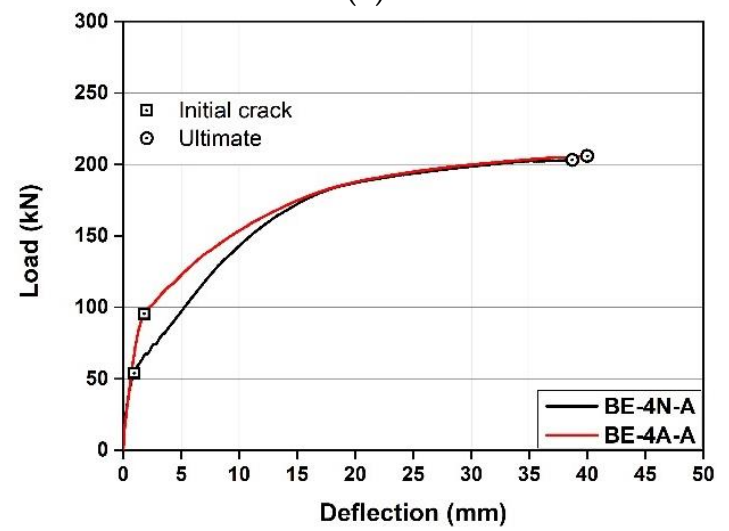

(c)

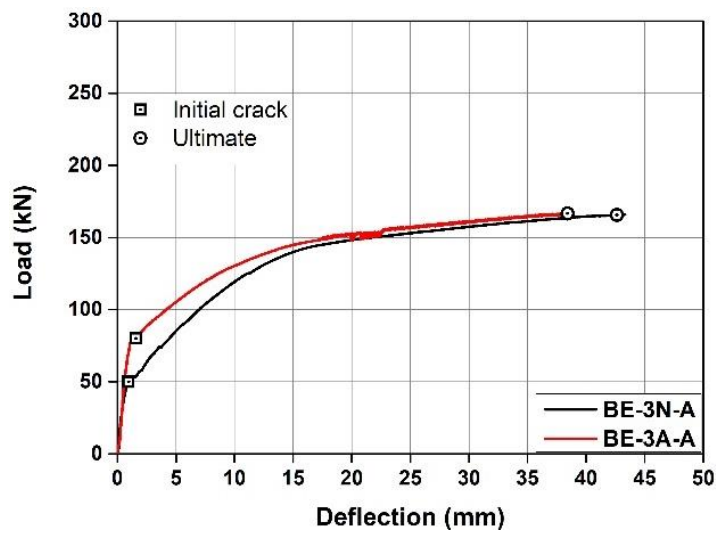

(b)

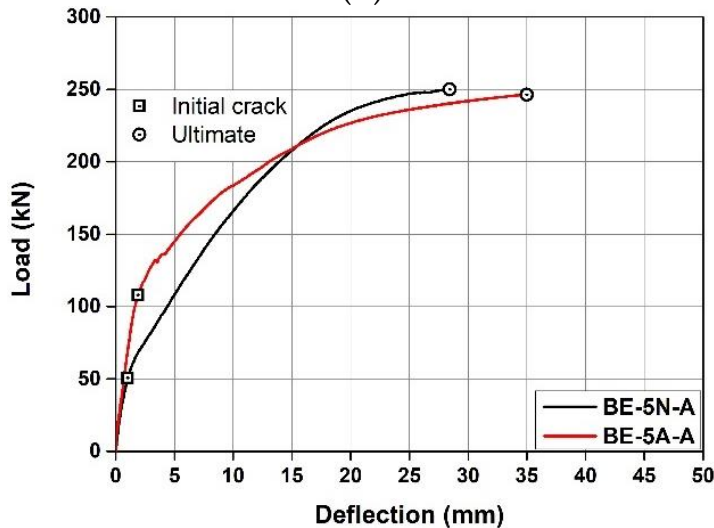

(d)

Figure 14. Load-deflection curves of the beams with and without Fe-SMA activation. (a) Beams BE2N-A and BE-2A-A. (b) Beams BE-3N-A and BE-3A-A. (c) Beams BE-4N-A and BE-4A-A. (d) Beams BE-5N-A and BE-5A-A.

\subsubsection{Effect of Fe-SMA Areas}

Figure 15 shows the load-deflection curves of the beam specimens with different areas of the Fe-SMA rebars. The initial crack loads were $42.31 \mathrm{kN}, 50.01 \mathrm{kN}, 53.92 \mathrm{kN}$, and $50.74 \mathrm{kN}$ for beams BE-2N-A, BE-3N-A, BE-4A-A, and BE-5A-A, respectively, when the areas of the nonactivated Fe-SMA rebars increased by about $6.7 \%$, i.e., the areas of the Fe-SMA rebars were increased by $100 \mathrm{~mm}^{2}$. As shown in Figure 15a, the initial flexural rigidity was significantly improved after the initial crack occurred as the cross-sectional areas of the Fe-SMA rebars increased. The ultimate loads of beams BE-2N-A, BE-3N-A, BE-4N-A, and BE-4N-A were $122.8 \mathrm{kN}, 165.9 \mathrm{kN}, 203.1 \mathrm{kN}$, and $250.0 \mathrm{kN}$, respectively, and 
they increased by an average of $26.8 \%$ when the cross-sectional areas of the Fe-SMA rebars were increased by $100 \mathrm{~mm}^{2}$. These results demonstrate that the cross-sectional areas of the Fe-SMA rebars affected the ultimate loads rather than the initial loads. Figure $15 \mathrm{~b}$ shows a comparison of the load-deflection curves of the beam specimens with the increasing crosssectional areas of the Fe-SMA rebars in the beam specimens with the activated Fe-SMA rebars. The initial cracking loads of beams BE-2A-A, BE-3A-A, BE-4A-A, and BE-4A-A were $62.5 \mathrm{kN}, 81.5 \mathrm{kN}, 95.4 \mathrm{kN}$, and $108.0 \mathrm{kN}$, respectively. That is, unlike the beam specimens with the nonactivated Fe-SMA rebars, the initial crack loads increased by an average of $20 \%$ when the cross-sectional area of the Fe-SMA rebars was increased by $100 \mathrm{~mm}^{2}$. In addition, the initial stiffness increased significantly after the initial crack occurred due to the increase in the cross-sectional area of the Fe-SMA rebars, as shown in the beams reinforced with the nonactivated Fe-SMA rebars. When the cross-sectional area of the Fe-SMA rebars was increased by $100 \mathrm{~mm}^{2}$, the ultimate loads increased by an average of $26.9 \%$, as in the case of the beam specimens reinforced with the nonactivated Fe-SMA rebars. Figure 16 shows a comparison of the initial crack loads and ultimate loads due to the increase in the cross-sectional area of the Fe-SMA rebars. The square and circle symbols in Figure 16 represent the initial crack loads and ultimate loads, respectively, and black and red colors, respectively, represent the activated and nonactivated Fe-SMA rebars in the beam specimens. As shown in Figure 16, the initial crack loads of the beam specimens reinforced with the activated Fe-SMA rebars were noticeably higher than those of the specimens reinforced with the nonactivated Fe-SMA rebars. However, significant increases in the ultimate loads were shown with the increasing Fe-SMA rebar area, regardless of activation of the Fe-SMA rebars. That is, it can be concluded that the activation of the Fe-SMA rebars has no significant effect on the ultimate loads.

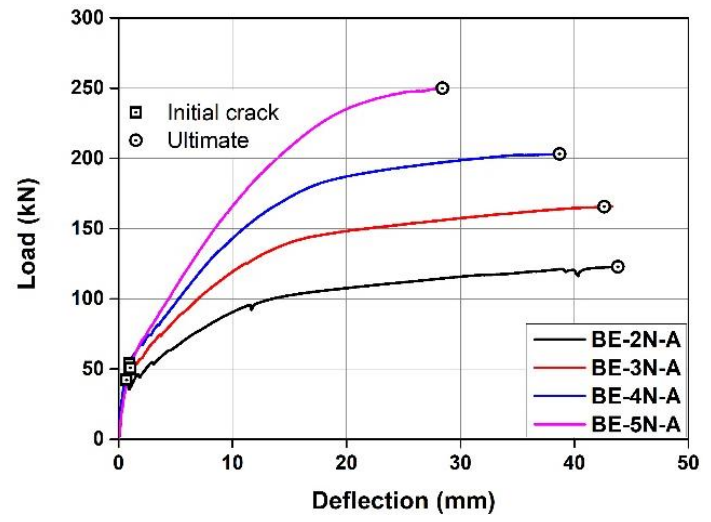

(a)

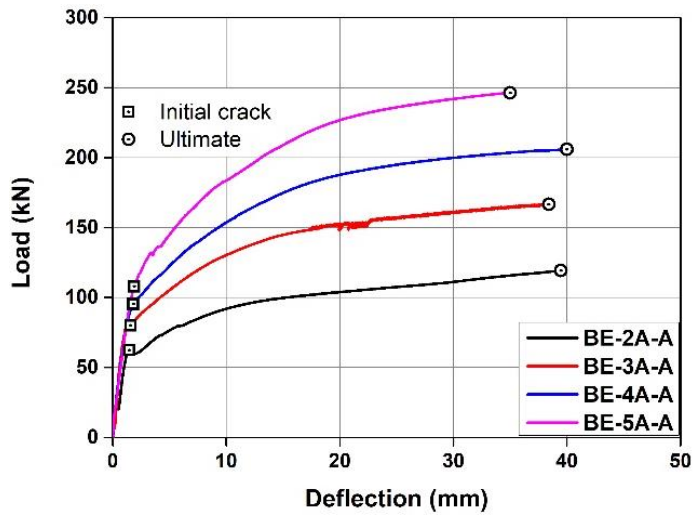

(b)

Figure 15. Load-deflection curves of the beams with and without activated Fe-SMA rebars. (a) Nonactivated beams. (b) Activated beams.

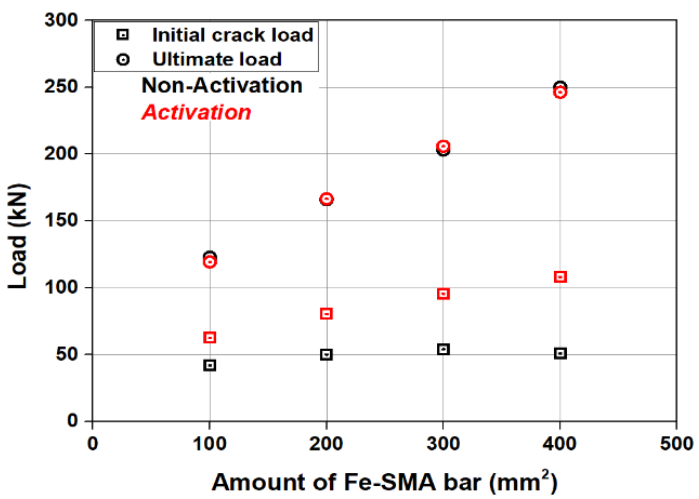

Figure 16. Initial crack loads and ultimate loads of the beam specimens with different areas of the Fe-SMA rebars. 


\subsubsection{Effect of Anchoring Fe-SMA Rebars}

Figure 17 shows a comparison of the load-deflection curves depending on usage of the anchoring device at the ends of the beam specimens. The anchoring device was applied to prevent slippage of the Fe-SMA rebars at both ends of the specimens. The initial crack on beam BE-3A-A, where the Fe-SMA rebars were fixed at both ends by the anchoring device, occurred at a load of $81.5 \mathrm{kN}$, whereas the initial crack on beam BE-3N-A, where the anchoring device was not used, occurred at a load of $80.1 \mathrm{kN}$. As shown in Figure 17, there was only an insignificant difference of $0.5 \%$ between the two initial crack loads on the load-deflection curves. The anchoring device for the Fe-SMA rebars did not impact the camber, as seen from a comparison of Figures 11 and 17. Thus, the compressive force by the activation of the Fe-SMA rebars was sufficiently introduced to the beam specimens without strength loss by slippage, which indicated that the anchoring device at both sides of the specimen was not required. However, this study used high-strength concrete with a compressive strength of $46.2 \mathrm{MPa}$, which might affect the bonding strength between the Fe-SMA rebars and concrete. Thus, the usability and effectiveness of the anchoring device for normal concrete should be researched as further study.

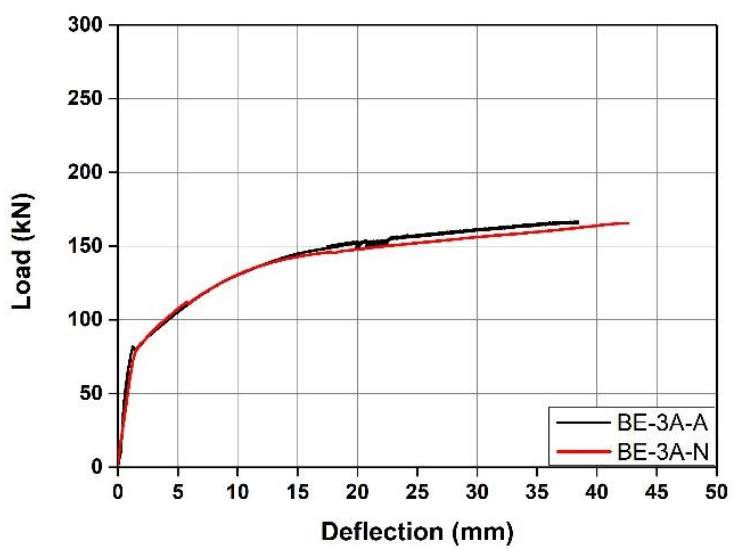

Figure 17. Load-deflection relationships of the beam specimens with different anchorage systems.

\subsubsection{Effect of Reactivating Fe-SMA Rebars}

When the Fe-SMA rebars are repeatedly reactivated, it is necessary to evaluate whether the compressive force repeatedly acts as the recovery stress is repeatedly generated. The effectiveness of the reactivated Fe-SMA rebars was evaluated on beam BE-3R-A by activating the Fe-SMA rebars four times. The evaluation was performed according to the following steps: (1) the Fe-SMA rebars were activated in accordance with Section 2.3 in this paper; (2) the beam specimen was loaded by $70 \%$ of its ultimate load. However, the last forth loading was carried out until the specimen was destroyed; (3) the applied load was completely removed from the beam specimen. As shown in Figure 18, the crack width at the central bottom of the beam specimen was measured by a clip-on gauge attached to the concrete crack during the reactivation of the Fe-SMA rebars. The crack control performance was evaluated by measuring the crack width on the specimen without applied load. Figure 19 shows the time-upward displacement relationships during reactivations of the Fe-SMA rebars. After the first reactivation, a camber of $0.204 \mathrm{~mm}$ was observed on beam BE-3R-A, which was not loaded. However, beam BE-3R-A loaded by $70 \%$ of its ultimate load showed cambers of $0.581 \mathrm{~mm}, 0.456 \mathrm{~mm}$, and $0.484 \mathrm{~mm}$, respectively, at the second, third, and fourth activations. These upward displacements were 285\%, 224\%, and 237\% larger than the value of $0.204 \mathrm{~mm}$ for the beam specimen with the Fe-SMA rebars that were activated once. The reasons for the larger cambers with reactivations of the Fe-SMA rebars were the reduced rigidity and bending crack development due to the iterations of the cyclic load. Furthermore, the cambers of beam BE-3R-A at the third and fourth reactivations were $21.5 \%$ and $16.7 \%$ smaller, respectively, than those after the second reactivation. This might be because the increased number of activations resulted in the decreases in the recovery stress 
of the Fe-SMA rebars. In this study, the relationship between the number of activations and the reduced recovery stress of the Fe-SMA rebars was not clearly demonstrated. Thus, further research on the correlation between them should be carried out.

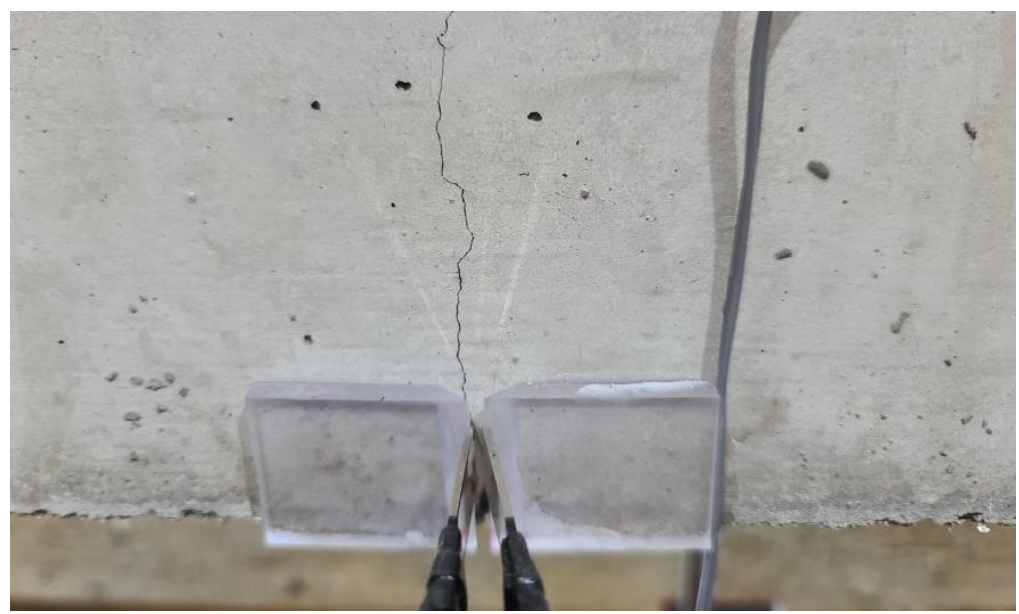

Figure 18. Overview of specimen crack recovery measurement due to Fe-SMA reactivation.

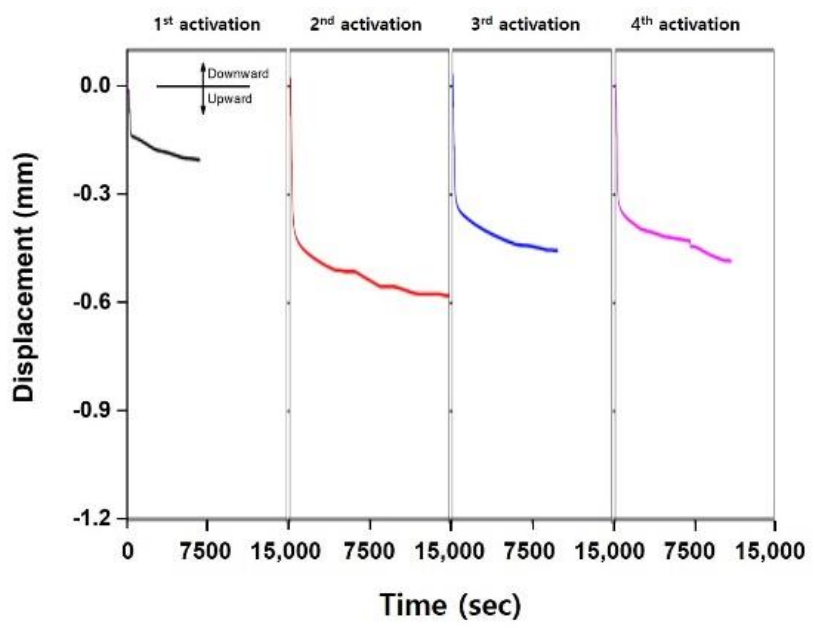

Figure 19. Time-displacement relationships of beam BE-3R-A with different numbers of reactivation.

Figure 20 shows the relationships of the surface crack width with the time in the tension zone of the beam specimen BE-3R-A during the activation of the Fe-SMA rebars. The flexural crack widths in beam BE-3R-A decreased by $0.06 \mathrm{~mm}$ to $0.071 \mathrm{~mm}$ from the second reactivation to the fourth reactivation of the Fe-SMA rebars. Those crack widths were smaller than the allowable crack width for all of the corrosion conditions considered in ACI 318 [28]. Therefore, it is determined that the surface crack width could be controlled by reactivating Fe-SMA rebars to be less than the allowable crack for preventing deterioration of the internal concrete and the embedded steel reinforcement even if cracks occurred. Figure 21 shows the load-deflection curves of beam BE-3A-A with Fe-SMA with one-time activation of the Fe-SMA rebars and of beam BE-3R-A with FE-SMA activated four times. As shown in Figure 21, beam BE-3R-A had a residual deformation after $70 \%$ of the ultimate load was removed, and some of the residual deformation was thereafter recovered by the reactivation of the Fe-SMA rebars. When $70 \%$ of the ultimate load was applied again to beam BE-3R-A, the load-deflection relationship returned to the previous $70 \%$ loading point for the corresponding displacement. Beam BE-3R-A with the Fe-SMA rebars where the Fe-SMA rebars were activated four times was loaded until the specimen showed failure in the compression zone. From the load-deflection curves in Figure 21, a comparison of the ultimate loads between beams BE-3R-A and BE-3A-A revealed only a $4.3 \%$ difference. For 
this result, it is noted that repeated activations of the Fe-SMA rebars did not substantially affect the flexural strength of the beam specimens.

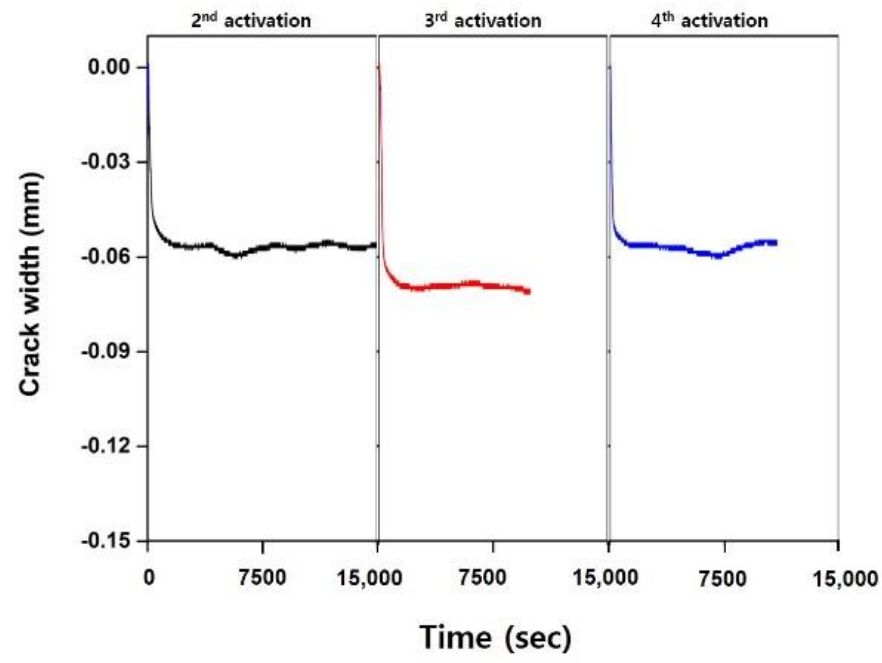

Figure 20. Time-crack width relationships of beam BE-3R-A with different numbers of reactivation.

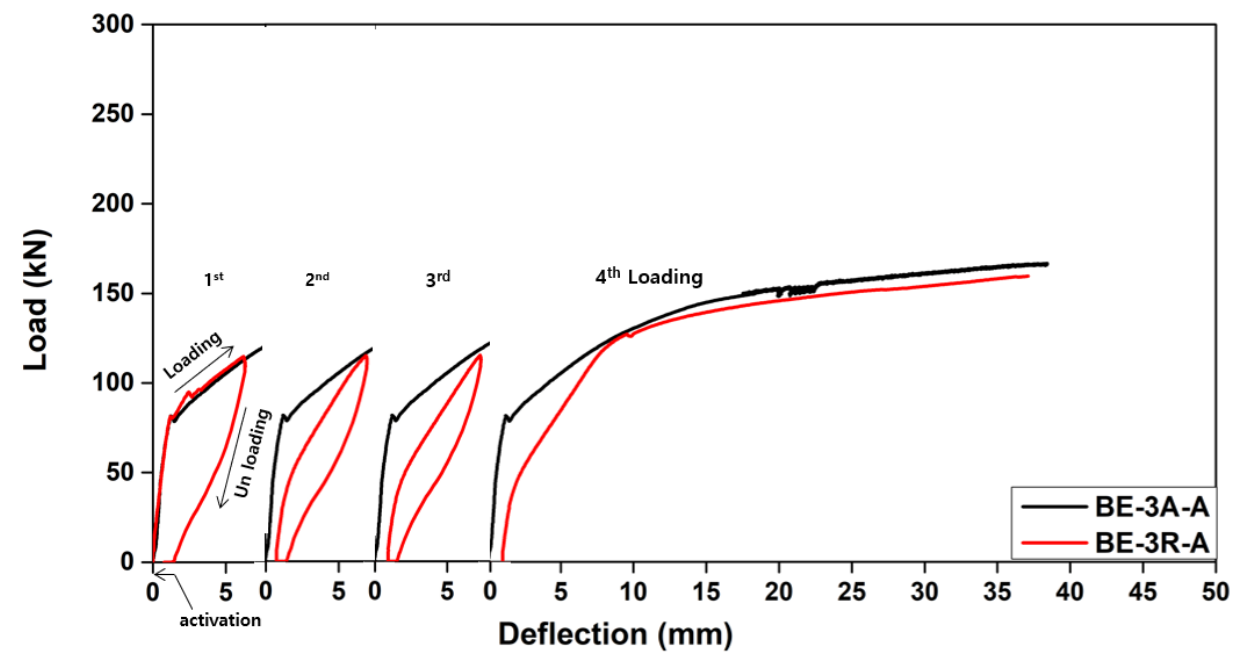

Figure 21. Load-deflection relationships of beams BE-3A-A and BE-3R-A.

\section{Conclusions}

In this paper, experimental investigations were conducted to evaluate the flexural behaviors of the concrete beams with embedded Fe-SMA rebars, and the following conclusions can be drawn.

1. When the Fe-SMA rebars were activated, downward deflections due to initial thermal expansion occurred, but cambers occurred due to the recovery stress of the Fe-SMA rebars. When the area of the Fe-SMA rebars was increased by $100 \mathrm{~mm}^{2}$, the camber increased by $0.093 \mathrm{~mm}$ on average.

2. The theoretically calculated camber of the concrete beam specimen by the activation of the Fe-SMA rebars was $22 \%$ lower than that from experimental test. This is because the heat of hydration activated the embedded Fe-SMA bars inside the concrete member. Thus, controlling the heat of hydration should be considered for casting a concrete member using Fe-SMA rebar as tensile reinforcement.

3. The initial cracking loads of the beam specimens with the activated Fe-SMA rebars were $47.6 \%$ to $112.8 \%$ higher than those of the nonactivated case. The increased initial crack loads were due to the introduction of the compressive force generated by the 
recovery stress of the Fe-SMA rebars. At the ultimate loads, the load differences were below 3\%, depending on whether the Fe-SMA rebars were activated.

4. Using an anchoring device to prevent slippage of the Fe-SMA rebars slightly improved the camber and increased the flexural strength of the beam specimens by less than $2 \%$. Thus, the bonding strength at the interface between the concrete and Fe-SMA rebars is sufficient to resist the slippage of the Fe-SMA rebars in the concrete beam members.

5. When the Fe-SMA bars were reactivated after applying $70 \%$ of the ultimate load, the deflection generated in the beam specimens was recovered by $0.456 \mathrm{~mm} \sim 0.581 \mathrm{~mm}$, and the crack widths were recovered by $0.060 \mathrm{~mm} \sim 0.071 \mathrm{~mm}$. Thus, the prestressed concrete using Fe-SMA rebars is expected to improve usability by recovering the lost prestressing force through reactivations even if the prestressing force is reduced due to various causes.

6. After four times of activation, it was confirmed that the load-displacement curves from the beam specimen with the rebars only activated once and the beam specimen with four-times-activated rebars were similar. In addition, the ultimate loads of the beam specimens with the reactivated rebars showed slight differences of only $4.3 \%$ compared to those of the beam specimen with the rebars activated four times. Therefore, it is noted that repeated activations on the Fe-SMA rebars may not substantially affect the flexural strength of the beam specimens.

7. As a result of the study, the prestressed concrete using Fe-SMA rebars is expected to be an alternative option that can solve various problems of the conventional prestressed concrete.

Author Contributions: K.-N.H. and Y.-M.Y. conceptualized the study; Y.-M.Y. obtained field data; Y.-M.Y. and S.-W.J. implemented data processing under the supervision of K.-N.H.; the original draft of the manuscript was written by K.-N.H. and Y.-M.Y. with editorial contributions from S.-W.J. and S.L. All authors have read and agreed to the published version of the manuscript.

Funding: This research was funded by the National Research Foundation of Korea (NRF) grant funded by the Korea Government (MSIT) grant number 2020R1A2C1003197.

Acknowledgments: This work was supported by the National Research Foundation of Korea (NRF) grant funded by the Korea Government (MSIT) (2020R1A2C1003197).

Conflicts of Interest: The authors declare no conflict of interest.

\section{References}

1. Afroughsabet, V.; Ozbakkaloglu, T. Mechanical and durability properties of high-strength concrete containing steel and polypropylene fibers. Constr. Build. Mater. 2015, 94, 73-82. [CrossRef]

2. Park, S.-G. Shear Strengthening Effect of Damaged Reinforced Concrete Beams Using Externally Post-Tensioning Steel Rods. Master's Thesis, Kyungpook National University, Kyungpook, Korea, 2018.

3. Ahmed, I.; Manzur, T.; Efaz, I.H.; Mahmood, T. Experimental Study on Bond Performance of Epoxy Coated Bars and Uncoated Deformed Bars in Concrete; Bangladesh University of Engineering \& Technology: Dhaka, Bangladesh, 2017.

4. Yoon, I.-S.; Kang, T.H.K.; Shin, H.-Y. Evaluation of corrosion prevention systems of strands for PSC structures. J. Korea Concr. Inst. 2019, 31, 557-565. [CrossRef]

5. Collins, M.P.; Mitchell, D. Prestressed Concrete Structures; Prentice-Hall: Hoboken, NJ, USA, 1991.

6. Kang, W.-H.; Han, M.-Y.; Lee, T.-S.; Rhu, Y.-M. A study on development of methods to rehabilitate the damaged prestressed concrete beam using glass fiber. J. Korea Concr. Inst. 1999, 11, 167-175.

7. Fawaz, G.; Murcia-Delso, J. Bond Behavior of Iron-Based Shape Memory Alloy Reinforcing Bars Embedded in Concrete. Mater. Struct. 2020, 53, 1-19. [CrossRef]

8. Hong, K.-N.; Lee, S.-G.; Yeon, Y.-M.; Jung, K.-S. Flexural response of reinforced concrete beams strengthened with near-surfacemounted Fe-based shape-memory alloy strips. Int. J. Concr. Struct. Mater. 2018, 12, 651-663. [CrossRef]

9. Lee, W.-J.; Webe, B.; Czaderski, C.; Motacalli, M.; Leinebach, C. Phase transformation behavior under uniaxial deformation of an Fe-Mn-Si-Cr-Ni-VC shape memory alloy. Mater. Sci. Eng. A. 2013, 581, 1-7. [CrossRef]

10. Rojob, H.; El-Hacha, R. Self-prestressing using iron-based shape memory alloy for flexural strengthening of reinforced concrete beams. ACI Struct. J. 2017, 114, 523-532. [CrossRef]

11. Lee, W.-J.; Weber, B.; Leinenbach, C. Recovery stress formation in a restrained Fe-Mn-Si-based shape memory alloy used for prestressing or mechanical joining. Constr. Build. Mater. 2015, 95, 600-610. [CrossRef] 
12. Sawaguchi, T.; Kikuchi, K.; Ogawa, K.; Kajiwara, S.; Ikeo, Y.; Kojima, M.; Ogawa, T. Development of prestressed concrete using Fe-Mn-Si-based shape memory alloys containing NbC. Mater. Trans. 2006, 47, 580-583. [CrossRef]

13. Czaderski, C.; Shahverdi, M.; Bronnimann, R.; Lenenbach, C.; Motavalli, M. Feasibility of iron-based shape memory alloy strip for prestressed strengthening of concrete structures. Constr. Build. Mater. 2014, 56, 94-105. [CrossRef]

14. Michels, J.; Shahverdi, M.; Czaderski, C. Flexural strengthening of structural concrete with iron-based shape memory alloy strips Struct. Concr. 2018, 19, 876-891. [CrossRef]

15. Enami, K.; Nagasawa, A.; Nenno, S. Reversible Shape Memory Effect in Fe-Base Alloys. Scr. Metall. 1975, 9, 941-948. [CrossRef]

16. Shahverdi, M.; Czaderski, C.; Motavalli, M. Iron-based shape memory alloys for prestressed near-surface mounted strengthening of reinforced concrete beams. Constr. Build. Mater. 2016, 112, 28-38. [CrossRef]

17. Michels, J.; Shahverdi, M.; Czaderski, C.; El-Hacha, R. Mechanical performance of iron-based shape-memory alloy ribbed bars for concrete prestressing. ACI Struct. J. 2015, 114, 523-532.

18. Hosseini, E.; Ghafoori, E.; Leinenbach, C.; Motavalli, M.; Holdsworth, S.-R. Stress Recovery and Cyclic Behaviour of an Fe-Mn-Si Shape Memory Alloy After Multiple Thermal Activation. Smart Mater. Struct. 2018, 27, 1-27. [CrossRef]

19. Hong, K.-N.; Lee, S.-G.; Han, S.H.; Yeon, Y.-M. Evaluation of Fe-based shape memory alloy (Fe-SMA) as strengthening material for reinforced concrete structures. Appl. Sci. 2018, 8, 730. [CrossRef]

20. Yeon, Y.-M.; Hong, K.-N.; Lee, S.H.; Ji, S.-W. Numerical study of RC beams strengthened with Fe-based shape memory alloy strips using the NSM method. Appl. Sci. 2021, 11, 6809. [CrossRef]

21. Shahverdi, M.; Michels, J.; Czaderski, C.; Motavalli, M. Iron-based shape memory alloy strips for strengthening RC members: Material behavior and characterization. Constr. Build. Mater. 2018, 173, 586-599. [CrossRef]

22. Kim, D.-H.; Park, C.-H.; Lee, J.-H.; Hong, K.-N.; Park, Y.-H.; Lee, W.-J. Microstructure shape memory behavior and mechanical properties of hot rolled Fe-17Mn-5Si-5Cr-4Ni-0.3C-1Ti shape memory alloy. Eng. Struct. 2021, 236, 112300. [CrossRef]

23. Montoya-Coronado, L.A.; Ruiz-Pinilla, J.G.; Ribas, C.; Cladera, A. Experimental study on shear strengthening of shear critical RC beams using iron-based shape memory alloy strips. Eng. Struct. 2019, 200, 109680. [CrossRef]

24. ASTM C39/C39M-17b. Standard Test Method for Compressive Strength of Cylindrical Concrete Specimens; ASTM International: West Conshohocken, PA, USA, 2017.

25. Lee, W.-J.; Partovi-Nia, R.; Suter, T.; Leinenbach, C. Electrochemical characterization and corrosion behavior of an Fe-Mn-Si shape memory alloy in simulated concrete pore solutions. Mater. Corros. 2015, 67, 839-846. [CrossRef]

26. Park, S.-J.; Yim, H.-J.; Kwak, H.-G. Evaluation of microcracks in thermal damaged concrete using nonlinear ultrasonic modulation technique. J. Korea Concr. Inst. 2012, 24, 651-658. [CrossRef]

27. Yeon, Y.-M. Evaluation of Prestressing Effect for Fe-based Shape Memory Alloy. Master's Thesis, Chungbuk National University, Cheongju-si, Korea, 2018.

28. ACI. Building Code Requirements for Structural Concrete; ACI 318-08; ACI: Farmington Hills, MI, USA, 2008. 